\title{
Psychosocial Rehabilitation
}

National Cancer Institute

\section{Source}

National Cancer Institute. Psychosocial Rehabilitation. NCI Thesaurus. Code C15423.

Programs, techniques, or processes of treatment by which individuals acquire psychological and social skills and attitudes which facilitate community interaction. (from PSY94) 